\title{
Effect of steam curing condition on the strength gain of mortar containing calcium nitrite based accelerator admixture
}

\author{
Abdul Ahmad Malikyar ${ }^{1 *}$, Yuhji Sudoh ${ }^{2}$, Nozomi Nakajima ${ }^{3}$, Shigeyuki Date ${ }^{4}$ \\ 1, 3,4 Civil Engineering Department, Tokai University, Kanagawa, Japan \\ ${ }^{2}$ Basic Chemical Department, Nissan Chemical Industries, Ltd
}

\author{
Index Terms \\ Compressive Strength \\ Steam Curing \\ Mortar \\ Calcium Nitrite \\ Accelerator Admixture
}

Received: 25 December 2016

Accepted: 13 January 2017

Published: 30 June 2017

\begin{abstract}
This study was carried out to investigate the effect of steam curing condition on the early and later age strength of mortar, which was added various dosages of Calcium Nitrite-Based accelerator. The study was performed on the specimens, which were subjected to the three different pre-curing time and exposed to the two different keeping curing times at the $45^{\circ} \mathrm{C}$ steam curing temperature. High early strength cement was used in this research experiment. From the obtained result, it was observed that the early (8-hour) strength of specimens exposed to the long keeping curing time (4.5, hour) is higher than the strength of specimens subjected to the short keeping curing time, ( 3 hours). Adversely, it is obtained that by increasing the ages of specimens, the strength gain goes up for the specimens exposed to short keeping curing time (3 hours), compared to the strength of the specimens exposed to longer keeping curing time (4.5 hours). Moreover, the obtained result indicates that the higher early and later ages strength of specimens was observed from the specimens which accompanied the pre-curing cycle of 90 minutes, compared to the strength of specimens, exposed to pre-curing cycle of 30 and 150 minutes. For all the cases, the result showed that by increasing the dosage of the accelerator admixture, the strength increased at the early and later ages.
\end{abstract}

\section{INTRODUCTION}

Up to now the success of precast concrete industry has been based on the economic advantage, namely, a highquality product and speed of construction. Today, however, there is an additional motive for using precast construction, with heightened awareness of traffic congestion, environmental pollution, natural resource depletion, and accompanying social problems. Precast concrete has become an attractive alternative to in situ construction methods, especially in large congested urban areas, [1]. Increase in the usage of the precast concrete element in construction field is coupled with increasing the precast concrete element production in precast concrete industry. Thus, recently most of the precast concrete production companies have increased the rate of production with good performance, and enhanced the early strength of precast element for safer and faster de-moulding. Different methods and important factors such as steam curing, and various accelerator admixtures have been applied, to improve the initial strength. Effect of curing condition and high steam curing temperature on the strength development of concrete has been studied by many researchers. Steam curing technique has been widely used in precast concrete production. It has been used to accelerate the strength gained at the early age because of the hydration rate of cement increased by heat treatment due to an impact of steam curing temperature, [2 and 3]. Curing temperature, pre-curing cycle, keeping curing time in the steam, and humidity, are the most im-

\footnotetext{
* Corresponding author: Abdul Ahmad Malikyar

${ }^{\dagger}$ Email: ahmad_ahmad2793@yahoo.com
} 
portant factors for the steam curing conditions that have been applied to speed up the initial strength, and any of them has the significant impact on the properties of concrete, [4-8]. Because of the lack of information on the effect of curing condition on the strength development of concrete while Calcium Nitrite is present as accelerator admixture, this research has been performed to study the effect of curing condition: keeping curing time and pre-curing cycle on the strength gain at early and later ages of specimens that contained various dosages of calcium nitrite-based accelerator. The aim of this study was to determine the optimum pre-curing cycle, and steam curing duration, while the steam curing temperature chosen was $45^{\circ} \mathrm{C}$, for the precast concrete industry, trying to bring speed to the early strength gain without harming the later age strength, for promoting the production rate of the precast concrete element.

\section{LITERATURE REVIEW}

Elevated temperature increases performance of the mortar at early ages but decreases at later age, [9]. It is observed that by delaying the steam curing operation by a period equal to the setting time of concrete, higher strengths were obtained in a shorter time, [10]. Keeping curing time in steam curing methods, effect on the strength gain of concrete, Increase in temperature, and total cycle time (which means higher energy and time consuming) led to higher immediate compressive strength. This could be due to the accelerated hydration reactions and rapid formation of Calcium-Silica-Hydrate (C-S-H gel), [11]. It was confirmed that high steam-curing temperature adversely affected concrete later-age strength. It was concluded, however, that under short curing periods and moderate temperatures, this adverse effect was primarily due to the lack of supplementary wet-curing, [12]. For accelerating the strength gain, different types of accelerator admixture have been used, [13, 14, and 15]. Even though the benefits of using accelerator admixture are obvious, helping the contractor to meet specified construction schedules. Calcium chloride is one of the most effective accelerators; it had been widely used for many decades, and however, due to its tendency to promote corrosion of steel, it is no longer recommended for use in steel-reinforced concrete, [16].

\section{EXPERIMENTAL STUDY}

Experimental study was carried out on the mortars containing three different dosages, $0 \%, 2 \%$, and $4 \%$ of Calcium Nitrite-based accelerator concentrated $45 \%$ weight.
The general formula of this accelerator is given in Table 1. High early strength cement was used in this study. The physical properties and chemical analyses are shown in Table 2 and Table 3. Fine aggregate used in this study is river sand from Kanagawa density $2.69 \mathrm{~g} / \mathrm{cm}^{3}$. (Saturated surface - dry condition). The water binder ratio was $30 \%$. Abbreviations and acronyms of materials which have been used for this study are illustrated in Table 4.

\section{A. Curing Method}

The steam temperature, steam curing duration, precuring time, and ambient temperature, are shown in figure 1and figure 2. In this study to investigate the influence of pre-curing time and keeping curing time on the strength of specimens at different ages while steam temperature was $45^{\circ} \mathrm{C}$, and ambient temperature was $20^{\circ} \mathrm{C}$, there have been two patterns of steam curing: pattern 1 and pattern 2 in which keeping curing on the steam temperature was 3 hours and 4.5 hours respectively. At the end of steam curing, the specimens were exposed to the air curing at ambient temperature $20^{\circ} \mathrm{C}$, and humidity was over $95 \%$, for 28 days.

TABLE 1

PROPERTIES OF (CALCIUM NITRITE BASED ACCELERATOR)

\begin{tabular}{lll}
\hline \hline Description & Total Concentration & Specific Gravity \\
\hline Amount & $45.1 \%$ & 1.43 \\
\hline \hline
\end{tabular}

\section{B. Compressive Test}

In the compressive strength test, for each series of mixing considered for the dosages of accelerator $0 \%, 2 \%$, and $4 \%$, and considering the duration of steam curing pattern 1 and pattern 2, for each period of pre-curing cycle, 9 specimens were casted and exposed to the steam curing according to the curing methods explained above. At the end of steam curing, the specimens were de-moulded.

TABLE 2

PHYSICAL PROPERTIES OF HIGH EARLY STRENGTH CEMENT)

\begin{tabular}{lll}
\hline \hline Description & Specific Surface $\left(\mathrm{cm}^{2} / \mathrm{g}\right)$ & Density $\left(\mathrm{g} /{ }^{3}\right)$ \\
\hline Amount & 4650 & 3.14 \\
\hline \hline
\end{tabular}

Among the 9 specimens, three specimens were crushed for each step of the crashing time, for early age (8, hour), and later ages ( 7 and 28 days). The reference specimens were casted and continuously cured at $22 \mathrm{C}^{\circ}$ and $95 \%$ 
relative humidity until they were tested in compression at ages 8 hours, 7 and 28 days.

TABLE 3

CHEMICAL COMPOSITION OF HIGH EARLY STRENGTH CEMENT

\begin{tabular}{lllll}
\hline \hline Description & Mgo & SO3 & CL-I & Ignition Loss \\
\hline Amount (\%) & 1.55 & 3.12 & 0.006 & 1.16 \\
\hline \hline
\end{tabular}

TABLE 4

ABBREVIATIONS AND ACRONYMS OF MATERIAL WHICH HAS BEEN USED FOR THIS STUDY

\begin{tabular}{|c|c|c|}
\hline Materials & Acronym & Properties \\
\hline Cement & $\mathrm{H}$ & $\begin{array}{lr}\text { High } & \text { early } \\
\text { strength Cement, } & \text { Censity3.14g/ } \mathrm{cm}^{3}\end{array}$ \\
\hline $\begin{array}{l}\text { Fine Aggre- } \\
\text { gate }\end{array}$ & $S$ & $\begin{array}{l}\text { River Sand from } \\
\text { Kanagawa density } \\
2.69 \mathrm{~g} / \mathrm{cm}^{3} \text {. (Satu- } \\
\text { rated surface-dry } \\
\text { condition) }\end{array}$ \\
\hline Admixture & $\mathrm{CN}$ & $\begin{array}{l}\text { Accelerator (Cal- } \\
\text { cium Nitrite based } \\
\text { concentrate } 45 \% \\
\text { weight) }\end{array}$ \\
\hline & SP & $8000 \mathrm{SS}$ (BASF) \\
\hline
\end{tabular}

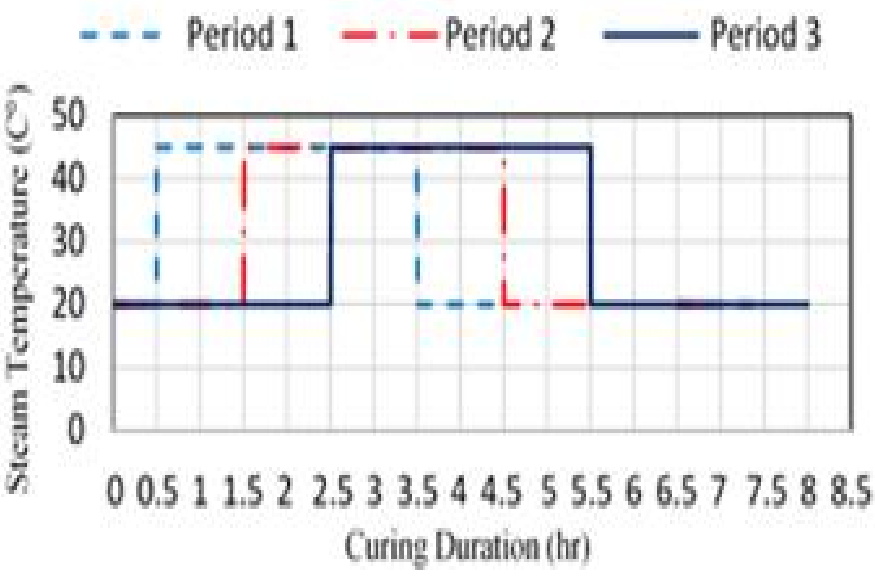

Fig. 1. Curing condition for pattern 1

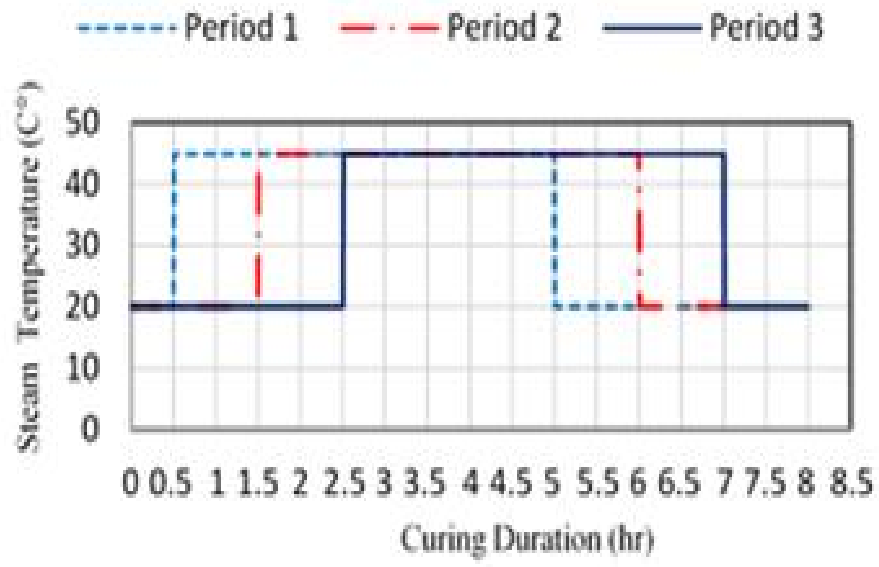

Fig. 2. Curing condition for pattern 2

\section{RESULT AND DISCUSSION}

\section{A. Effect of Accelerator Admixture and Steam Tempera- ture on the Compressive Strength at Early and later Ages}

From the obtained result, it is determined that Calcium Nitrite accelerator admixture has a significant effect on the strength gain of mortar in the different regime of steam curing. It is obtained that by increasing the dosage of accelerator admixture, the compressive strength increased at different ages. From the result, it is also obtained that the high early and later age compressive strength was found for specimens made with $4 \% \mathrm{CN}$ accelerator admixture.

TABLE 5

VARIATION IN STRENGTH BASED CN ACCELERATOR AND STRENGTH OF CONTROL SPECIMEN

\begin{tabular}{llllll}
\hline \hline CN (\%) & Pre-Curing & Cure Duration & \multicolumn{3}{l}{ Compressive Strength $\left(\mathrm{N} / \mathrm{mm}^{2}\right)$} \\
\hline & & & $8(\mathrm{hr})$ & 7 (days) & $28($ days $)$ \\
0 & $90(\mathrm{~min})$ & $3(\mathrm{hr})$ & 29.07 & 85 & 91 \\
4 & $90(\mathrm{~min})$ & $3(\mathrm{hr})$ & 56.71 & 101.67 & 108.54 \\
Control & & Water Curing & 3.45 & 95.25 & 109 \\
0 & $90(\mathrm{~min})$ & $4.5(\mathrm{hr})$ & 40.02 & 89.15 & 94.79 \\
4 & $90(\mathrm{~min})$ & $4.5(\mathrm{hr})$ & 65.33 & 98.97 & 103.33 \\
\hline
\end{tabular}

Moreover, the compared result between specimens made with $0 \%$ accelerator and exposed to steam curing and specimens exposed to water curing showed that the early strength of specimens exposed to steam curing is higher than the strength of specimens cured in water, and the later ages strength was higher for the specimens cured in water; it is due to negative effect of steam temperature on the later ages strength. From the obtained result, it is also determined that by adding $4 \% \mathrm{CN}$ accelerator admix- 
ture, the early strength is higher, and later age strength is almost same as the later age strength of control specimens (Table 5 and Figure 3).

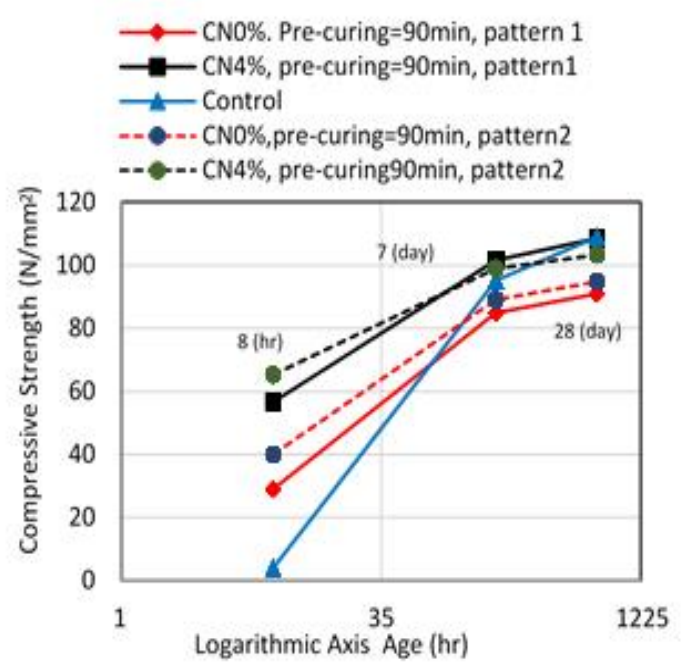

Fig. 3. Variation in compressive strength based accelerator dosage and compressive strength of control specimens

\section{B. Effect of Keeping Curing Time on the Strength Gain at Different Ages}

The experimental result indicated that the early compressive strength for specimens produced with $\mathrm{CN}$ accelerator and exposed to the longer duration in steam curing (pattern 2), was higher than the compressive strength of specimens exposed to the shorter duration in steam curing (pattern 1), but at later ages of 7 days and 28 days, compressive strength of specimens exposed to the short keeping curing time pattern 1 was slightly higher than the strength of specimens traveled in longer keeping curing time pattern 2. It is probably due to the effect of duration of heat treatment on the rate of hydration based on longer steam curing.

The compressive strength result for early and later ages of specimens made with $4 \%$ and exposed in pattern 1 and 2, is illustrated in Table 6 and Figure 4. Moreover, from the result in Figure 4 and Table 6, it is obtained that the compressive strength of specimens for early and later ages is higher for the specimens conducted in longer keeping steam curing while no accelerator admixture was added in these specimens. It means that if no accelerator admixture is added, the higher strength at different ages will be obtained for the specimens exposed to the long duration in steam curing.
TABLE 6

VARIATION IN COMPRESSIVE STRENGTH AT DIFFERENT AGES

FOR SPECIMEN EXPOSED TO THE PATTERN 1 AND 2

\begin{tabular}{llllll}
\hline \hline CN (\%) & Pre-Curing & Cure Duration & \multicolumn{3}{c}{ Compressive Strength $\left(\mathrm{N} / \mathrm{mm}^{2}\right)$} \\
\hline & & & $8(\mathrm{hr})$ & 7 (days) & 28 (days) \\
0 & $90(\mathrm{~min})$ & $3(\mathrm{hr})$ & 29.07 & 85 & 91 \\
4 & $90(\mathrm{~min})$ & $3(\mathrm{hr})$ & 56.71 & 101.67 & 108.54 \\
0 & $90(\mathrm{~min})$ & $4.5(\mathrm{hr})$ & 40.02 & 89.15 & 94.79 \\
4 & $90(\mathrm{~min})$ & $4.5(\mathrm{hr})$ & 65.33 & 98.97 & 103.33 \\
\hline \hline
\end{tabular}

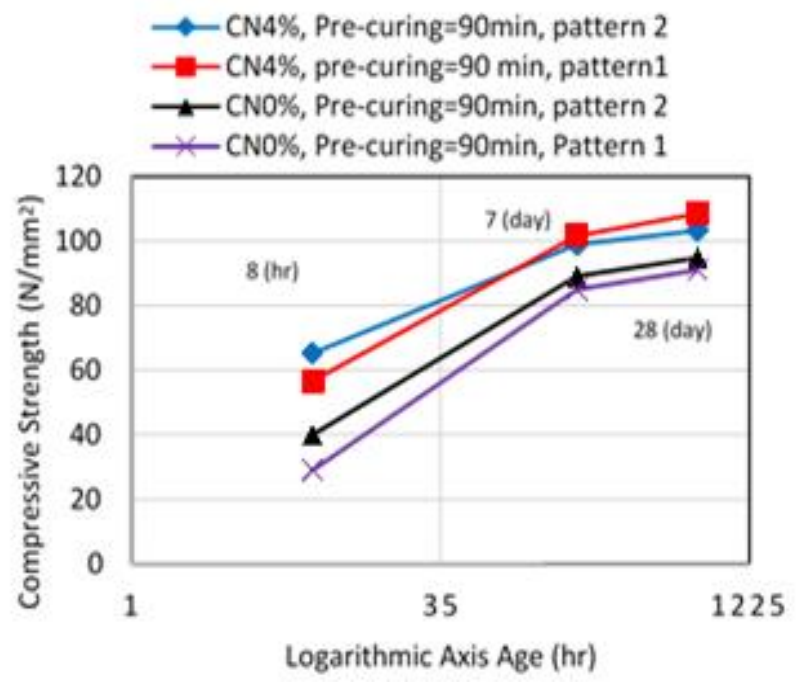

Fig. 4. Variation in compressive strength at early age 8 hours and later age 28 days based pre-curing period for specimens exposed to the steam curring pattern 2

\section{Effect of Pre-Curing Cycle on the Early and Later Ages Strength Gain}

Some precast concrete plants make energy-saving and reduce the production time. They expose the precast concrete element in steam curing treatment immediately after casting the concrete in mould. In this study, the precuring cycles were selected $(30,90$, and 150$)$ minutes, to find out the optimum pre-curing cycle. According to the result from this study, among three pre-curing periods, it is obtained that the short pre-curing cycle (30 minutes) causes slightly lower compressive strength for early and later ages. It can be explained that if the steam curing application starts before the sitting time of the concrete, the surface of mortar specimens hardens earlier while the inner is still plastic. As the internal temperature due to steam application and heat of hydration increases, the inner fresh concrete will try to expand [17]. Moreover, during the heat treatment, the difference in the thermal expansion coefficient of the concrete ingredients can lead to micro-cracking 
and porosity [18]. But the result indicated that the early strength of specimens exposed to the 90 minutes pre-curing cycle was approximately same as the strength result for specimens conducted to the longer pre-curing cycle of 150 minutes. Table 7 and Figure 5 show the effect of pre-curing cycle on the strength gain for specimens at the ages of 8 hours and 28 days, which were conducted in steam curing pattern 2 .

TABLE 7

VARIATION IN COMPRESSIVE STRENGTH AT EARLY AGE 8 HOURS AND LATER AGE 28 DAYS BASED PRE-CURING PERIOD FOR SPECIMENS EXPOSED TO THE STEAM CURING PATTERN 2

\begin{tabular}{lllll}
\hline \hline CN (\%) & Pre-Curing & Cure Duration & \multicolumn{2}{l}{ Compressive Strength $\left(\mathrm{N} / \mathrm{mm}^{2}\right)$} \\
\hline & & & $8(\mathrm{hr})$ & 28 (days) \\
0 & 30 & 4.5 & 32.36 & 86.46 \\
2 & 30 & 4.5 & 53.12 & 94 \\
4 & 30 & 4.5 & 63.54 & 102.79 \\
0 & 90 & 4.5 & 40.02 & 94.79 \\
2 & 90 & 4.5 & 56.95 & 99.38 \\
4 & 90 & 4.5 & 65.33 & 103.33 \\
0 & 150 & 4.5 & 38.71 & 93.33 \\
2 & 150 & 4.5 & 57.66 & 96 \\
4 & 150 & 4.5 & 68.08 & 102.79 \\
\hline \hline
\end{tabular}

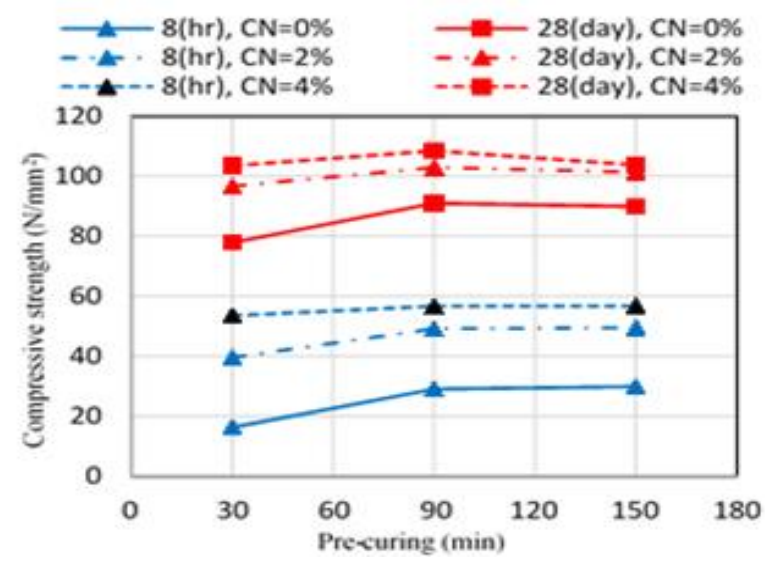

Fig. 5 . Variation in compressive strength at early age 8 hours and later age 28 days based pre-curing period for specimens exposed to the steam curring pattern 2

Table 8 and Figure 6 illustrated the result of the effect of the pre-curing cycle $(30,90$, and 150$)$ minutes, on the compressive strength gain for specimens at ages of 8 hours and 28 days, exposed to the steam curing pattern 1. The obtained result has shown that the high compressive strength at different ages, 8 hours and 28 days was found for the specimens exposed to the pre-curing cycle of $90 \mathrm{~min}$ - utes compared to the result which was obtained with precuring cycles of 30 minutes and 150 minutes. Thus, among the mentioned three pre-curing cycles, it is obtained that 90 minutes' pre-curing cycle is the optimum pre-curing cycle, for all the cases with and without using $\mathrm{CN}$ accelerator admixture.

TABLE 8

VARIATION IN COMPRESSIVE STRENGTH AT EARLY AGE 8 HOURS AND LATER AGE 28 DAYS BASED PRE-CURING PERIOD FOR SPECIMENS EXPOSED TO THE STEAM CURING PATTERN 1

\begin{tabular}{lllll}
\hline \hline CN (\%) & Pre-Curing & Cure Duration & \multicolumn{2}{l}{ Compressive Strength $\left(\mathrm{N} / \mathrm{mm}^{2}\right)$} \\
\hline 0 & 30 & 3 & 16.32 & 77.9 \\
2 & 30 & 3 & 29.07 & 96.67 \\
4 & 30 & 3 & 29.91 & 103.54 \\
0 & 90 & 3 & 29.07 & 91 \\
2 & 90 & 3 & 49.22 & 103 \\
4 & 90 & 3 & 56.71 & 108.54 \\
0 & 150 & 3 & 29.91 & 90 \\
2 & 150 & 3 & 49.56 & 101.38 \\
4 & 150 & 3 & 56.77 & 103.73 \\
\hline \hline
\end{tabular}



Fig. 6. Variation in Compressive strength at early age 8 hours and later age 28 days based pre-curing period for specimens exposed to the steam curing pattern 1

Fig. 6. Variation in compressive strength at early age 8 hours and later age 28 days based pre-curing period for specimens exposed to the steam curring pattern 1

\section{CONCLUSION}

Effect of steam curing condition on the strength gain of mortar containing Calcium Nitrite-based accelerator admixture has been successfully studied. From the result of the study presented earlier, the following conclusions are offered:

Calcium Nitrite accelerator increases the strength gain of mortar at different ages; higher strength at early and later age obtained for specimens produced with $4 \%$ accelerator. So the optimum dosage was found to be $4 \%$. 
High early strength was obtained for the specimens exposed to the longer steam curing duration ( 4.5 hours) and the later age strength was found to be higher for specimens exposed to the shorter steam curing ( 3 hours).

High compressive strength was obtained when the specimens were subjected to steam curing after 90 minutes' pre-curing cycle. So the optimum pre-curing period is 90 minutes.

The result of study suggests that $\mathrm{CN}$ could be used as hardening accelerator while the rate of steam temperature is low. It is recommended to investigate the influence of Calcium Nitrite as accelerator admixture on the microstructure of concrete, in future study.

\section{REFERENCES}

[1] A. A. Yee and P. H. D. Eng, "Social and environmental benefits of precast concrete technology," PCI Journal, vol. 46, no. 3, pp. 14-19, 2001.

DOI: $10.15554 /$ pcij.05012001.14.19

[2] H. A. Toutanji and Z. Bayasi, "Effect of curing procedures on properties of silica fume concrete," Cement and Concrete Research, vol. 29, no. 4, pp. 497-501, 1999.

DOI: $10.1016 / \mathrm{S} 0008-8846(98) 00197-5$

[3] B. Liu, Y. Xie and J. Li, "Influence of steam curing on the compressive strength of concrete containing supplementary cementing materials," Cement and Concrete Research, vol. 35, no. 5, pp. 994-998, 2005. DOI: 10.1016/j.cemconres.2004.05.044

[4] S. Türkel and V. Alabas, "The effect of excessive steam curing on Portland composite cement concrete," Cement and Concrete Research, vol. 35, no. 2 , pp. 405-411, 2005 . DOI: $10.1016 /$ j.cemconres.2004.07.038

[5] S. Erdogdu and S. Kurbetci, "Optimum heat treatment cycle for cements of different type and composition," Cement and Concrete Research, vol. 28, no. 11, pp. 1595-1604, 1998.

DOI: $10.1016 / \mathrm{S} 0008-8846(98) 00134-3$

[6] M. F. Ba, C. X. Qian, X. J. Guo and X. Y. Han, "Effects of steam curing on strength and porous structure of concrete with low water/binder ratio," Construction and Building Materials, vol. 25, no. 1, pp. 123-128, 2011. DOI: $10.1016 /$ j.conbuildmat.2010.06.049

[7] T. Boubekeur, K. Ezziane and E. H. Kadri, "Estimation of mortars compressive strength at different curing temperature by the maturity method," Construction and
Building Materials, vol. 71, pp. 299-307, 2014.

DOI: $10.1016 /$ j.conbuildmat.2014.08.084

[8] Ö. Çakir and F. Aköz, "Effect of curing conditions on the mortars with and without GGBFS," Construction and Building Materials, vol. 22, no. 3, pp. 308-314, 2008. DOI: 10.1016/j.conbuildmat.2006.08.013

[9] U. Ghani, F. Shabbir and K. M. Khan, "Effect of temperature on different properties of concrete," in 31st Conference on Our World in Concrete and Structures, Singapore, 2006.

[10] T. K. Erdem, L. Turanli and T. Y. Erdogan, "Setting time: An important criterion to determine the length of the delay period before steam curing of concrete," Cement and Concrete Research, vol. 33, no. 5, pp. 741-745, 2003. DOI: $10.1016 / S 0008-8846(02) 01058-X$

[11] A. A. Ramezanianpour, M. H. Khazali and P. Vosoughi, "Effect of steam curing cycles on strength and durability of SCC: A case study in precast concrete," Construction and Building Materials, vol. 49, pp. 807-813, 2013. DOI: $10.1016 /$ j.conbuildmat.2013.08.040

[12] I. Soroka, C. H. Jaegermann and A. Bentur, "Short-term steam-curing and concrete later-age strength," Materials and Structures, vol. 11, no. 2, pp. 93-96, 1978.

DOI: $10.1007 / \mathrm{BF} 02478955$

[13] J. Dransfield, "Admixture technical sheet-ATS4, accelerating admixture," Cement Admixture Association, West Midlands, UK, 2012.

[14] M. Cheikh-Zouaoui, N. Chikh, S. Aggoun and R. Duval, "Studies on effects of activators on properties and mechanism of hydration of Portland cement," in International Conference on Admixtures-Enhancing Concrete Performance, University of Dundee, Scotland, UK, 2005.

[15] J. A. Naqash, Z. B. Bhat, M. I. Malik, S. Ahmad and D. Kumar, "Effect of accelerating admixture on properties of concrete," IOSR Journal of Engineering, vol. 4, no. 3, pp. 48-55, 2014. DOI: 10.9790/3021-04314855

[16] R. Myrdal, "Accelerating admixtures for Concrete, Concrete Innovation Centre (COIN)," SINTEF Building and Infrastructure, Trondheim, Norway, 2007.

[17] K. Jung-Min and K. Myung-Ho, "The study about indoor temperature effect on productivity by brainwave type of occupants," International Journal of Technology and Engineering Studies, vol. 2, no. 4, pp. 117-124, 2016. DOI: $10.20469 /$ ijtes.2.40004-4

[18] J. Alexanderson, "Strength loss in heat cured concrete," in Conference of Swedish Cement and Concrete Research Institute, Stockholm, Sweden, 1972. 